\title{
REPRESENTAÇÕES DISCURSIVAS DA POBREZA E GRAMÁTICA
}

\section{(Discursive representation of poverty)}

\author{
Denize Elena Garcia da SiLVA \\ (Universidade de Brasília)
}

\section{Introdução}

O propósito de vincular representações discursivas da pobreza à gramática justifica-se por duas razões no contexto deste trabalho. Por um lado, busco discutir o aspecto funcional da linguagem, associado a situações que implicam a representação da pobreza no discurso, sobretudo, na voz de adolescentes que vivem em situação de privação social e extrema carência. Por outro lado, procuro investir na relação que existe entre as bases funcionais da linguagem sugeridas por Halliday (1994), dentro da Linguística Sistêmico-Funcional (LSF) e estudos voltados para a area da Análise de Discurso Crítica (ADC), desenvolvidos por Fairclough (2003) e Wodak (2004) entre outros, o que significa enfocar a linguagem como sistema e como comportamento, sondá-la desde a interioridade (gramática) até sua dimensão exterior (discurso).

Trato, aqui, de buscar a correlação entre a estrutura linguística e a estrutura social com o propósito de, conforme palavras de Wodak (2004: 225), "investigar criticamente como a desigualdade social é expressa, sinalizada, constituída, legitimada pelo discurso", mediante a análise de entrevistas-narrativas realizadas com dois adolescentes, cujas trajetórias de vida configuram a rota da pobreza. Cabe ressaltar que, no centro da proposta da ADC, encontra-se o incentivo para pesquisas cujos resultados permitam ao investigador apontar ou, em condições propícias, combater os efeitos maléficos da sociedade, razão pela qual constitui um lema constante para analistas críticos a proposta fairclougheana de que toda pesquisa para ser útil deve resultar numa prática social transformadora. Isso, porque os discursos implicam, simultânea e dialeticamente, práticas sociais: como maneiras de (inter-)agir, de representar e de se identificar no mundo.

Resulta que tais maneiras, dentro da proposta de Fairclough (2003), encontram-se associadas a três elementos de ordens de discurso - gêneros, 
discursos, estilos - e aos três principais significados da linguagem - acional, representacional e identificacional. Não obstante, deve-se ressaltar que esses três tipos de significados têm sua gênese nas macrofunções da linguagem propostas por Halliday (1994) e rediscutidas por Halliday \& Matthiessen (2004) dentro da Linguística Sistêmico-Funcional (LSF), da qual tratarei a seguir, mediante um breve paralelo com a ADC.

\section{A LSF e os significados do discurso sob a lupa da ADC}

A Linguística Sistêmico-Funcional aponta três macrofunções simultâneas da linguagem: a ideacional (enfoque na oração como processo); a interpessoal (enfoque na oração como ato de fala); e a textual (enfoque na oração como mensagem). Destaco, aqui, os processos de transitividade da língua, os quais se encontram associados à função ideacional, que consiste na expressão do conteúdo, da experiência do falante/escritor em relação ao mundo real (incluindo as noções de tempo e espaço) e ao mundo interior de sua própria consciência. Na perspectiva da LSF, enquanto a função constitui uma propriedade fundamental da linguagem, a gramática pode ser compreendida como sistema de opções disponíveis na língua, sendo que o falante ou escritor realiza suas escolhas dentro desse sistema, sempre num contexto de situação social de fala ou de escrita, de modo que "um simples enunciado contextualizado, veiculado em uma oração, permite-nos aproximar do lado funcional da linguagem", conforme registrado em Silva (2005:39).

Com base no princípio de que a linguagem estrutura a experiência e contribui para determinar nossa visão de mundo, sugere Halliday (1994) que se pode identificar em uma oração uma transitividade evidenciada por vários tipos de processos - material, comportamental, mental, verbal, relacional e existencial - com seus significados e participantes característicos, bem como as circunstâncias que os envolvem. Deve-se enfatizar, ainda, que a teoria sistêmica hallidayana configura uma proposta que envolve o estudo da linguagem em sua interioridade, mas que também leva em conta as escolhas, as opções, as necessidades, bem como os propósitos dos falantes, o que se reflete na exterioridade da linguagem. Em Silva (2007, 2008), busco correlacionar a estrutura linguística e a estrutura social. O caminho para tanto tem sido justamente o de explorar, ou estreitar cada vez mais, o diálogo teórico-metodológico da ADC com a LSF, mediante a análise linguístico-discursiva de dados colhidos em contextos de situação que envolvem a pobreza como pano de fundo. 
Em seu modelo de análise de discurso textualmente orientada para a pesquisa social, Fairclough (2003) sugere que um texto, além de envolver simultaneamente as funções ideacional, interpessoal (identitária e relacional) e textual, deve ser examinado sob o prisma de três tipos de significados do discurso, ou seja, como ação (por meio de gêneros), representação (por meio de discursos) e identificação (por meio de estilos), que são os três elementos de ordens de discurso. Explica o autor que cada ordem de discurso encerra gêneros discursivos característicos, que articulam discursos e estilos de maneira relativamente estável num determinado contexto sóciohistórico e cultural. Cabe lembrar, ainda, que gêneros, discursos e estilos constituem elementos de ordens do discurso, categorias diferentes de nomes e orações, que são elementos de estruturas linguísticas. Comenta Fairclough (2003:28) que analisar textos em termos dos significados do discurso, isto é, na interface entre ação e gêneros, representação e discursos, bem como entre identificação e estilos, implica uma perspectiva social detalhada. Isso nos permite não só abordar os textos em termos dos três principais aspectos do significado, e das maneiras como são realizados em traços lingüísticos nos textos, mas também estabelecer a conexão entre um evento social concreto e práticas sociais mais abstratas.

Ainda que a relação entre os significados do discurso seja dialética, traços semânticos, gramaticais e lexicais dentro de textos podem ser associados, em princípio, a significados particulares. Essa especificidade explica-se pelo fato de gêneros se realizarem nos textos em formas e significados acionais, assim como discursos, em formas e significados representacionais, e estilos, em formas e significados identificacionais. Isso implica que traços linguísticos específicos (tais como vocabulário, relações semânticas e gramaticais) são, em princípio, moldados por significados particulares (Silva e Ramalho, 2008).

Nos exemplos apresentados adiante, utilizo algumas categorias de análise que correspondem, especialmente, a formas e significados representacionais, razão pela qual tenho investido numa transdiciplinaridade entre estudos da linguagem e do discurso como prática social, sobretudo, com respeito à categoria da representação. Mas, por agora, destaco a base metodológica proposta por Halliday (2002a) para a interpretação de textos. 


\section{Pontos a serem observados na interpretação de textos}

Em primeiro lugar, o analista do discurso deve-se pautar por um princípio norteador (selecionar e desenvolver o que for necessário para o propósito em questão) - como, por exemplo, configurações discursivas sobre o problema da pobreza na adolescência.

Em segundo lugar, como enfatiza Halliday, a análise textual deve constituir um trabalho de interpretação - determinadas representações podem implicar, por exemplo, expressões linguístico-discursivas permeadas por um tipo de argumentação que coloca, na maioria das vezes, um problema social na esfera de um plano ou domínio abstrato.

A análise léxico-gramatical deve constituir uma parte essencial dessa tarefa. Porém, mais além do nível léxico-gramatical, a proeminência da representação da pobreza pode ser encontrada em discursos particulares, como se poderá observar a seguir.

\section{Geração e análise dos dados}

Os exemplos, apresentados a seguir, configuram recortes de duas entrevista-narrativas, colhidas entre os meses de janeiro e maio de $2007 .{ }^{4} \mathrm{~A}$ técnica de entrevistas tem por objetivo gerar informações ou narrativas que podem ser usadas para entender a perspectiva do participante sobre as atividades envolvidas. ${ }^{5}$ Segundo Jovchelovitch (2000:143), "narrativas são uma das principais formas discursivas nas quais as representações sociais se desenvolvem", pois elas estão sempre sob uma forma discursiva.

Busca-se, aqui, enfocar segmentos em que aparecem marcas da interação dialógica (entrevistador e colaborador da pesquisa) na transcrição dos dados, o que favorece o olhar analítico tanto nos processos de transitividade (função ideacional) quanto nos significados identificacional e repre-

\footnotetext{
4 Os dados analisados fazem parte da dissertação de mestrado de Miguel Ângelo Moreira (2007). Por motivos éticos, o pesquisador identifica com pseudônimos os adolescentes entrevistados.

5 Gaskell (2002:66) ressalta que "a entrevista qualitativa fornece os dados básicos para o desenvolvimento e a compreensão das relações entre os atores sociais e sua situação. O objetivo é uma compreensão detalhada das crenças, atitudes, valores e motivações, em relação aos comportamentos das pessoas em contextos sociais específicos."
} 
sentacional da linguagem, assim como nas representações sociais. O propósito é colher os significados da linguagem a partir da gramática da experiência de adolescentes.

Deve-se aclarar, de início, que as estruturas aqui trabalhadas configuram uma aplicação do modelo proposto por Halliday (1994) em sua "gramática da experiência”. As nomenclaturas empregadas são traduções de termos do inglês, aplicadas ao português do Brasil, no que concerne aos processos verbais, aos participantes envolvidos, bem como às circunstâncias associadas.

A sequência discursiva abaixo mostra uma atividade comum que tem sido assumida por milhares de jovens pobres cada vez mais incorporados pela condição de pré-adulto.

Eu vigiava carro... Eu chegava lá... Todo mundo me conhecia, já... Os menino que vigiava lá também... Aí, chegava lá era uma vez de cada... Um carro de cada... Deixava perfeito. Se num deixá!... Esperava a outra vez dele... /..../ Eu perguntava se queria que vigiasse... /.... "Não, pode vigiá aí"... e outros falava "Não"... "Não, vô voltá rápido"... "Não, tem gente dentro do carro"... /.... A Ah, de vez em quando... dava um real... oitenta centavo, cinqüenta... /.../ Ab, a primeira vez eu cheguei... O amigo meu já vigiava já... Aí, eu fui mais ele... Aí, comecei... Aí, o primeiro dia que fui, eu ganhei dezoito reais... Aí, eu dei quinze pra minha mãe e fiquei com três... Aí, eu continuei ino... ((O que você encontrou na rua que mais te atraiu?)) Não, porque eu fui a primeira vez e ganbei um dinheirinho... Aí, eu continuei ino... /.../ Ab, eu achei bom, né... ganhá um dinheirim... ((Aí, você pensou em fazer o que na hora?)) $A h, o$ primeiro dia que eu fui... eu comprei uma caixa de chocolate... Aí, eu fui... A caixa de chocolate era. Ela era três reais, que era pequenininha... Aí, eu comprei e levei o resto tudo pra minha mãe... /.../ Eu até tive vontade de trabalbá...

(MATEUS, 14 ANOS)

No discurso de Mateus, a maioria dos segmentos oracionais envolve processos do tipo material (em negrito). Observa-se também que o ator envolvido nas orações está relacionado à própria experiência física do narrador. Os verbos de processo material narram a experiência do adolescente com o mercado de trabalho. O jovem descreve detalhadamente a rotina diária na atividade de "vigiar carro" e mostra que o trabalho parece ser uma condição natural de alguns jovens de famílias pobres, tanto que eles seguem conscientemente as regras daquela atividade laboral, como exemplificam os excertos seguintes - "Aí, chegava lá era uma vez de cada... Um carro de cada... Deixava perfeito, se num deixá!... Esperava a outra vez dele... /..../ Eu perguntava se queria que vigiasse...". 
Destacam-se, também, os processos do tipo verbal, que projetam citações. ${ }^{6}$ Tais processos retratam a rotina de trabalho a partir da relação do jovem com os possíveis "clientes", caracterizada pelo processo verbal " $f a$ lar", como é possível notar nos trechos seguintes - "Não, pode vigiá aí"...e outros falava "Não"... "Não, vô voltá rápido"... "Não, tem gente dentro do carro...". A "fala" da sociedade revela que a atividade desenvolvida não é considerada uma profissão, já que não há garantia de remuneração. A expressão circunstancial - "de vez em quando..." - associada ao processo material "dar" denuncia uma condição de mendicância, o que fica ilustrada na estrutura abaixo:

(1) Ah, de vez em quando... dava um real... oitenta centavo, cinqüienta...

\begin{tabular}{|c|c|c|c|c|}
\hline$A h$ & de vez em quando & (alguém) & dava & um real... oitenta centavo, cinqüenta \\
\hline $\begin{array}{c}\text { conector } \\
\text { pragmático }\end{array}$ & $\begin{array}{c}\text { circunstância de } \\
\text { tempo }\end{array}$ & ator & $\begin{array}{c}\text { processo } \\
\text { material }\end{array}$ & meta \\
\hline
\end{tabular}

Não obstante, o adolescente, ao dar ênfase a sua experiência como "vigia de carros", revela que a necessidade de "ter" atiça sua vontade de inserir-se socialmente no mundo capitalista/consumista por meio do trabalho, como pode ser observado nas estruturas a seguir:

(2) Porque eu fui a primeira vez e ganbei um dinheirinho...

\begin{tabular}{|c|c|c|c|c|c|c|}
\hline Porque & $e u$ & $f u i$ & a primeira vez & $e$ & ganhei & um dinheirinho \\
\hline conector & ator & $\begin{array}{r}\text { processo } \\
\text { material }\end{array}$ & circ. de tempo & conector & $\begin{array}{c}\text { processo } \\
\text { material }\end{array}$ & meta \\
\hline
\end{tabular}

(3) Aí, eu continuei ino...

\begin{tabular}{|c|c|c|c|}
\hline$A \hat{i}$ & eu & continuei & ino \\
\hline \multirow{2}{*}{ conector pragmático } & \multirow{2}{*}{ ator } & finito & predicador \\
\cline { 3 - 4 } & & \multicolumn{2}{|c|}{ processo material } \\
\hline
\end{tabular}

\footnotetext{
${ }^{6}$ De acordo com Eggins (2004:236), "assim como os processos mentais, os verbais formam orações complexas, que projetam uma segunda oração por citação ou relato".
} 
(4) Ah, eu achei bom, né... ganhá um dinheirim

\begin{tabular}{|c|c|c|c|c|c|c|}
\hline$A h$, & $e u$ & $a c h e i$ & bom, & né & ganhá & um dinheirim \\
\hline \multirow{2}{*}{$\begin{array}{c}\text { conector } \\
\text { pragmático }\end{array}$} & experienciador & $\begin{array}{c}\text { processo } \\
\text { mental }\end{array}$ & fenômeno & $\begin{array}{c}\text { conector } \\
\text { pragmático }\end{array}$ & $\begin{array}{c}\text { processo } \\
\text { material }\end{array}$ & meta \\
\cline { 5 - 7 } & & & & & \multicolumn{2}{|c|}{ oração projetada } \\
\hline
\end{tabular}

Observa-se, inicialmente, que o elemento verbal "ganhar", em (2), traduz a experiência concreta do adolescente com o mundo capitalista. O desejo de inserir-se socialmente para fugir das amarras da pobreza alimenta a vontade de continuar a atividade laboral, como revela a estrutura (3). Nessa perspectiva, o jovem deixa transparecer essa vontade através do processo mental "achei", em (4), o que ilustra um comentário avaliativo que mostra a tentativa de inserção no mundo capitalista.

De acordo com Bauman (1999:88), "a maneira como a sociedade atual molda seus membros é ditada primeiro e acima de tudo pelo dever de desempenhar o papel de consumidor". Nesse sentido, a busca de inserção na sociedade consumista parece saciar o desejo de "ter" antes apagado pela condição de pobreza e motiva o adolescente a abrir mão da condição de criança para assumir o papel de adulto. Vejamos a estrutura oracional seguinte, cujos elementos exibem a resignação frente às exigências do mundo capitalista:

(5) Eu até tive vontade de trabalhá...

\begin{tabular}{|c|c|c|c|}
\hline$E u$ & até & tive & vontade de trabalhá \\
\hline identificado & conector pragmático & processo relacional & identificador \\
\hline
\end{tabular}

O segmento oracional em (5), mais que ilustrar o discurso de um adolescente que expressa sua experiência de viver nas ruas em condição de trabalhador-adulto, permite também observar uma capacidade de resignação e, ao mesmo tempo, marcar uma auto-identidade. No comentário avaliativo acima, a preposição "atê" enfatiza uma informação que o adolescente considera relevante e imprime uma relação de equivalência - o desejo de trabalhar, reflexo da pobreza, apaga a condição de menoridade.

Como bem observa Fairclough (2003:103), "o trabalho de estabelecimento de equivalências e diferenças torna claro que é simultaneamente 
uma apropriação de um novo discurso por membros da comunidade local de gerenciamento, pegando-a e colocando-a em relação ao que já existe". Trata-se de um narrador, cuja identidade parece encontrar-se fragmentada em função da situação de resignação à condição prematura de adulto, ainda que seja uma criança. Nesse sentido, parece que não é o jovem que é atraído para as ruas, mas um complexo de situações que o empurram. A rua, entre outras coisas, funciona como um meio de sobrevivência para os adolescentes. O desejo de "ter" alimenta a permanência dos jovens na rua.

O excerto seguinte, de outra entrevista-narrativa, mostra detalhadamente o que o adolescente fala sobre a aprendizagem nas ruas.

((O que você acha que aprende nas ruas?)) Acho que eu queria sê... Faz altas coisa. Soltá pipa (xxx) Vendê chiclete, essas coisa... Aí, vai... Aí, vai à vida ((Você acha que só aprende coisa boa na rua?)) Não... mas tem outras coisa que a gente aprende de ruim, né... Coisas que a gente aprende... A gente já começa a usar essas coisa... Roubá... essas coisas assim... Usar drogas, essas coisas... Roubá... Cheirá... Assaltá ônibus, essas coisas assim... Engraxá sapato... Só isso...

(TIAGO EVANGELISTA, 14 ANOS)

No relato de Tiago Evangelista, a predominância de processos materiais, que dão ênfase a ações no mundo físico, está relacionada à narração de fatos que concretizam de maneira dura sua vida nas ruas. Além disso, destaca-se, no primeiro segmento oracional, um comentário avaliativo que expressa um desejo implícito que está ligado ao mundo da consciência, como exibem as estruturas abaixo:

(6) Acho que eu queria sê...

\begin{tabular}{c|c|c|c|c|c|}
\hline (eu) & acho & $q u e$ & $e u$ & $q u e r i a$ & $s \hat{e}$ \\
\hline \multirow{2}{*}{ experienciador } & $\begin{array}{c}\text { processo } \\
\text { mental }\end{array}$ & conector & experienciador & processo mental & processo relacional \\
\cline { 4 - 6 } & & \multicolumn{4}{|c|}{ fenômeno (oração projetada) } \\
\cline { 3 - 6 }
\end{tabular}

(7) Faz altas coisa...

\begin{tabular}{c|c|}
\hline Faz & altas coisas \\
\hline processo material & meta \\
\hline
\end{tabular}


(8) Soltá pipa

\begin{tabular}{|c|c|}
\hline Soltá & pipa \\
\hline processo material & meta \\
\hline
\end{tabular}

(9) Vendê chiclete

\begin{tabular}{|c|c|}
\hline Vendê & chiclete \\
\hline processo material & meta \\
\hline
\end{tabular}

Do ponto de vista do significado identificacional da linguagem, o segmento oracional (6) envolve um comentário avaliativo que pressupõe o desejo do adolescente de retornar à infância, o que corresponde a uma resposta à clássica pergunta "o que você quer ser quando crescer?". As orações com processos mentais projetam sentimentos que estão relacionados à busca de uma identidade pessoal, caracterizada pelo verbo "ser". O segmento oracional seguinte, em (7), sintetiza as ações desejadas e mostra que a busca do exercício da infância (8) concorre com a necessidade de sobrevivência (9). Nesse sentido, o adolescente mostra que sua identidade parece encontrar-se fragmentada em função do desejo de ser criança ("soltá pipa") e a necessidade de trabalhar ("vendê chiclete"), o que parece ser uma projeção do reflexo das exigências impostas pela própria família quando empurra os jovens às ruas e lhes delega obrigações. Como bem observa Rajagopalan (2003:71), "as identidades estão sendo adaptadas e adequadas às novas circunstâncias que vão surgindo".

Outro aspecto concernente às exigências impostas pelas ruas, é o que esse ambiente ensina aos jovens, para os quais a rua é um lugar onde só aprendem coisas ruins, com exceção do trabalho que é visto como algo positivo, pois possibilita a contribuição no orçamento familiar. No relato de Tiago Evangelista, a predominância de processos materiais, ligados ao mundo físico, revela o que o jovem afirma ter vivenciado nas ruas. Trata-se de ações projetadas pelos desejos ("eu queria sê") do adolescente acerca do que pode encontrar nas ruas.

No relato do adolescente mencionado acima, a escolha da expressão pronominalizada "a gente" denuncia o discurso de representação social de 
um grupo de jovens excluídos do direito de exercer a infância. Nesse sentido, a expressão a gente funciona como ator que elabora ou realiza as ações produzidas pelos processos materiais usar (drogas), roubar, cheirar, assaltar, engraxar, como destacado no exemplo em questão. Nessa perspectiva, o adolescente parece apagar a subjetividade enfatizada na estrutura (6) e assume a voz dos jovens que vivem em situação de rua para mostrar o que eles aprendem fora do universo da família. O discurso de Tiago Evangelista apenas revela o conhecimento elaborado e distribuído socialmente acerca do que os jovens aprendem nas ruas, sobretudo, o que concerne à violência.

\section{Considerações finais}

Busquei discutir, neste artigo, o aspecto funcional da linguagem associado a situações que implicam a representações da pobreza no discurso, sobretudo, na voz de atores sociais que vivem em situação de privação social e extrema carência, como é o caso dos adolescentes cujas entrevistasnarrativas foram analisadas. À guisa de conclusão, endosso as palavras de Miguel Angelo Moreira (2007:203), para quem o trabalho de pesquisa com os adolescentes, "terá alcançado seus objetivos se as representações sociais de família e pobreza, veiculadas na gramática das experiências de vida dos adolescentes entrevistados, servirem para acentuar uma aversão forte, em cada leitor, pelas injustiças e desigualdades sociais".

E-mail: denizelena@gmail.com

\section{REFERÊNCIAS BibLIOGRÁFICAS}

BAUER, Martin \& GASKeLL, George (org.) 2002. Pesquisa qualitativa com texto, imagem e som: um manual prático. Tradução de Pedrinho A. GuareschiPetrópolis, RJ: Vozes.

Bauman, Z. 1999. Globalização: as consequências humanas. Tradução de Marcus Penchel. Rio de Janeiro: Jorge Zahar Ed.

Fairclough, N. 2003. Analysing discourse: textual analysis for social research. Londres; New York: Routledge.

Halliday, M. A. K.1994. An introduction to Functional Grammar. Londres: Edward Arnold. 
2002a. On Grammar, vol 1. Londres/Nova York: Continuum.

. \& Matthiessen, C. M. I. M. 2004. An introduction to Functional Grammar. Londres: Edward Arnold.

Jovchelovitch, S. \& BAuer, M. 2002. Entrevista narrativa. In: Martin Bauer e George Gaskell, Pesquisa qualitativa com texto, imagem e som: um manual prático. Tradução de Pedrinho A. Guareschi - Petrópolis, RJ: Vozes.

Moreira, M. A. 2007. Ruptura familiar e pobreza: a gramática da experiência no discurso de adolescentes. Brasília: Universidade de Brasília, tese de dissertação inédita.

Wodak, R. 2004. Do que trata a ACD - um resumo de sua história, conceitos importantes e seus desenvolvimentos. Linguagem em (Dis)curso. Carmen Rosa Caldas-Coulthard e Debora de Carvalho (orgs.). Análise Crítica do Discurso, v.4/ Epecial: 223-243.

Rajagopalan, K. 2003. Por uma linguística crítica: linguagem, identidade e a questão da ética.São Paulo: Parábola Editorial.

SiLva, D.E.G. 2005. Discurso e gramática: motivações cognitivas e interacionais. In: Denize Elena Garcia da Silva (org.), Nas instâncias do discurso: uma permeabilidade de fronteiras. Brasília: Editora Universidade de Brasília, Oficina Editorial do Instituto de Letras.

. A pobreza no contexto brasileiro: da exclusão econômica e social à ruptura famliar. In: Discurso y Sociedad, vol 2(2) p. 265-296. www.dissoc.org

Silva, D.E.G e Ramalho, V. 2008. Análise de Discurso Crítica: representações sociais na mídia. In: Gláucia Lara, Ida L. Machado e Wander Emediato (orgs.) Análises do discurso hoje. vol.2. Rio de Janeiro: Nova Fronteira (Lucerna), p. 265-292. 